\title{
TOPIC IN REVIEW
}

\section{Simplifying physicians' response to domestic violence}

Physicians are called on, through guidelines such as those published by the American Medical Association in 1992, ${ }^{1}$ to play a large role in identifying, intervening in, and following up on cases of partner abuse. Yet, even the first step of intervention, screening, is difficult for most physicians. Victims are still not asked about abuse in their relationships and are not receiving the health care they need. ${ }^{2-11}$

Physicians want to help victims of domestic violence but face complex barriers to doing so. One way to increase physicians' effectiveness in this area is to clearly define and limit their role in intervening with victims.

\section{METHODS}

The model we suggest here was developed from the literature on domestic violence and health care, our collective experiences teaching domestic violence intervention to medical students and practicing physicians, and our recent research with physicians who intervene with victims and with survivors who have been helped by physicians. ${ }^{12-16}$ To locate relevant literature, we conducted MEDLINE searches with the key word "domestic violence," followed by "guidelines," "screening," "intervention," and "barriers." We focused on research published following the publication of the 1992 guidelines for physicians regarding domestic violence intervention. ${ }^{1}$

\section{INCREASING EFFECTIVENESS BY FOCUSING PHYSICIANS’ ROLE}

We propose limiting physicians' tasks to the following 4 areas, using the acronym AVDR: asking patients about abuse; validating the message that battering is wrong and confirming the patient's worth; documenting presenting signs, symptoms, and disclosures; and referring victims to domestic violence specialists. Within this limited role, physicians provide medical care but rely on community or in-house experts on domestic violence to do most of the intervening.

\section{HOW AVDR WORKS \\ Asking}

When physicians routinely ask about domestic violence, they are successfully fulfilling a major part of the intervention, regardless of what the patient discloses. Screening sends the message that battering is wrong and is a health care issue. Physicians with expertise in domestic violence say that they normalize domestic violence by including it among other safety questions - for example, the use of seat belts and gun safety - and by saying or implying that they routinely ask all their patients about domestic violence. ${ }^{12}$

\section{Summary points}

- Defining and limiting physicians' role in intervening with victims of domestic violence increases their effectiveness

- Physicians should ask patients about abuse; validate that battering is wrong; document signs, symptoms, and disclosures; and refer victims to domestic violence specialists (AVDR)

- With this approach, physicians' time in providing patients quality care is greatly reduced

- An AVDR approach to domestic violence could be integrated into managed care delivery systems

- Universal screening, identifying risk factors, validating patients, and documenting abuse will help prevent further abuse

- We are all responsible for solving the problem of domestic violence

Making the question a normal part of the history taking helps physicians reduce their own and patients' discomfort with screening for domestic violence.

Experienced physicians and advocates advise that physicians always ask about abuse in a private, confidential setting, using nonjudgmental tones and language. Family members should never be used as translators. Physicians need to develop their own way of asking patients about abuse. "How are things at home?" is a standard screening question that can be embedded in other questions on safety and used as an opening to more specific questions about abuse. Here are some examples of how to ask the questions:

The next questions are about safety. Do you remember to wear seat belts? Is there anything particularly stressful going on now? How are things at home?

Domestic violence can be a problem in many people's lives, so I now ask every patient I see about safety in their relationships.

I see patients in my practice who are being hurt or threatened by someone they love. Is this happening to you? Has this ever happened to you?

Adding one question about domestic violence to the routine health assessment is an important first step in improving health care for victims ${ }^{17}$ and for teaching people that partner abuse is a public health problem.

\section{Validating}

When asking patients about domestic violence, physicians need to acknowledge that battering is wrong. They need
Barbara Gerbert

James Moe

Nona Caspers

Division of Behavioral

Sciences

University of California,

San Francisco

601 Montgomery St,

Suite 810

San Francisco, CA

94111

Patricia Salber

The Permanente

Company

280 W MacArthur Blvd

Oakland, CA

94611-5693

Mitchell Feldman

Division of General

Internal Medicine

University of California

San Francisco, CA

94143

Karen Herzig

Amy Bronstone

Division of Behavioral Sciences

University of California

San Francisco, CA

94111

Correspondence to:

Dr Gerbert

gerbert@itsa.ucsf.edu

Funding: This project has been supported by grant 1 R01 MH51580

from the National

Institute of Mental

Health.

Competing interests:

None declared

West J Med

2000;172:329-331 


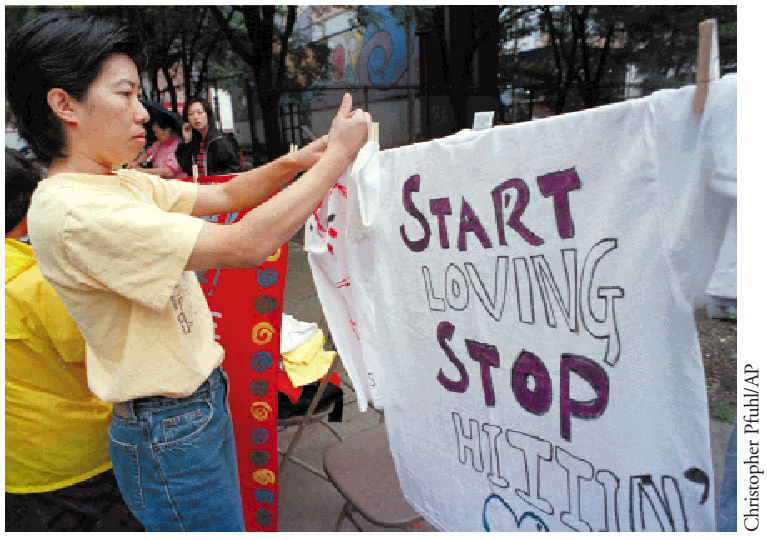

Physicians often face complex barriers to helping victims of domestic violence

to also confirm their patients' worth. Clear, validating messages include compassionate statements that take the blame off the victim: "You didn't cause this; it isn't your fault." "You do not deserve to be hit or hurt, no matter what happened." "I am concerned about your safety and well-being."

Physicians should periodically revisit the topic of domestic violence, expressing concern for the patient's health and safety and offering hope for the future.

Validation does not depend on direct disclosure by the patient. Survivors report that validation helps them even when they have not directly disclosed the abuse and the health care professional has not directly identified the abuse. ${ }^{13}$ One survivor reported that she and her health care professional danced around the issue of abuse, but that the health care professional still provided validation by being nonjudgmental and caring:

She [the health care professional] helped me realize that I was not alone, that no matter how well I thought I was hiding it [the abuse], I wasn't hiding it, that I may as well just say the words because people knew anyway. She is the only health care provider who did that. It was one more drop of water in the bucket until it was spilling over, so in that way it helped me a lot.

\section{Documenting}

Physicians must document the presenting signs and symptoms of abuse as well as any disclosures about the abuse by the victim. The organization Physicians for a Violence-free Society ${ }^{18}$ recommends that notations in the medical record be specific and detailed and that physicians ask patients for specific names, locations, and witnesses. The victim's direct words should be denoted with quotation marks; a patient's own words, especially those that contain names, places, and specific behaviors, carry more weight in legal cases than physicians' summary statements. For example, "My husband, John Doe, kicked me and pushed me down the stairs last night" is better than "aggravated assault."
The physician may need to complete body maps and take photographs to document specific injuries. Cameras that develop pictures instantly should be readily available in all health care settings because pictures offer an inviolable record of the abuse. The process of documenting abuse can serve to validate the patient if accompanied by genuine, nonjudgmental statements of concern.

\section{Referring}

Physicians should refer patients who have been abused to community advocates or on-site specialists. Physicians working in group or solo practices with no resources on site could refer the patient, as the last part of the health care visit, to an advocate for victims of domestic violence at a local agency, shelter, or hot line. Ideally, physicians would have access to trained advocates or dedicated staff, health educators, or social workers available on site or on call around the clock. These specialists would take complete histories of the abuse, thoroughly document additional disclosures of the abuse, maintain the medical record, assess for safety and develop a safety plan if indicated, refer to community services, develop a follow-up plan, report to the police if required to by state law, and inform the physician about all interventions. If the identifying physician is the patient's primary care physician, he or she would follow up on domestic violence as a health issue in the patient's life and provide ongoing validation to lay the groundwork for change. Change should take place at the patient's pace.

This referral approach is the same as referring a patient to a specialist for the treatment of a physical condition. Physicians with expertise in domestic violence report that when they directly connect the victim to an on- or off-site domestic violence specialist, they "feel relief' and are reassured that the patient will receive the additional services needed. If the patient is not ready to speak with a specialist in domestic violence, the physician must offer the patient telephone numbers for referrals ${ }^{19}$ and try to assess her immediate safety needs. ${ }^{20}$

\section{REDUCING BARRIERS FOR PHYSICIANS}

Physicians report that they do not intervene with victims because of lack of time, lack of education in domestic violence, lack of knowledge of legal issues, cultural barriers to communication, and patients' perceived unresponsiveness. ${ }^{6,11,21,22}$ Sugg and Inui ${ }^{23}$ interviewed primary care physicians and found that they likened a discussion of domestic violence to "opening Pandora's box." Their analysis suggests that talking about partner abuse with patients makes physicians fearful and uncomfortable and threatens their role as a competent professional. Physicians also report that major barriers to identifying domestic violence cases come from battered patients' silence about the 
abuse and their reluctance to disclose it. ${ }^{24-26}$ Patients report that they do not disclose because of fear of their partner's retaliation, shame, humiliation, denial, and a belief that health care professionals cannot do much to help them. ${ }^{14,27,28}$

With the AVDR approach, the time required of physicians - compared with that required by current recommendations - to ensure that battered patients receive quality care is greatly reduced. In addition, physicians do not need extensive training in or knowledge about domestic violence. Universal, routine screening, proposed as part of the asking and validating process, relieves physicians of the responsibility for determining whom to screen for domestic violence and thus reduces cultural barriers, personal discomfort, and the fear of offending patients. We agree with Chez and Jones, ${ }^{29}$ who suggest that only with universal screening will physicians become more comfortable with questioning their patients about partner abuse.

With a specialist providing the necessary care, physicians may avoid the fear or frustration arising from their inability to fix the problem quickly. Some physicians with expertise in this area report having reframed their role in helping victims: "I've let go of having to fix or cure or even know if it's really happening."12 Warshaw ${ }^{30}$ pointed out that working as a member of an advocacy team empowers physicians and enhances their feelings of self-efficacy.

\section{AVDR COMPLEMENTS CURRENT HEALTH CARE TRENDS}

An AVDR approach could be integrated into managed care systems. Universal screening, identifying risk factors, validating patients, and documenting abuse put the physician in a proactive role and aim to prevent further abuse. As recently proposed by Salber, ${ }^{15}$ specialists in domestic violence could be advocates who market themselves as vendors of services for managed care organizations.

\section{CONCLUSIONS}

Physicians have a crucial role in the health care system's response to domestic violence. A physician may be the only health care professional a battered person sees, and all physicians see patients who have been battered. We suggest that the inadequate response of many physicians to domestic violence is due in large part to unrealistic expectations. The AVDR approach sends a clear message to overwhelmed physicians and the health care system: it is not physicians' responsibility to solve the problem of domestic violence; it is all of our responsibility. We hope this approach contributes to the evolution of the health care system's response to this pervasive public health problem.

References

1 American Medical Association's Council on Scientific Affairs. Violence against women: relevance for medical practitioners. JAMA 1992;267:3184-3189.
2 Abbott J, Johnson R, Koziol-McLain J, et al. Domestic violence against women: incidence and prevalence in an emergency department population. JAMA 1995;273:1763-1767.

3 Mazza D, Dennerstein L, Ryan V. Physical, sexual and emotional violence against women: a general practice-based prevalence study. Med $J$ Aust 1996;164:14-17.

4 McGrath M, Hogan F, Peipert J. A prevalence survey of abuse and screening for abuse in urgent care patients. Obstet Gynecol 1998;91:511-514.

5 Caralis P, Musialowski R. Women's experiences with domestic violence and their attitudes and expectations regarding medical care of abuse victims. South Med J 1997;90:1075-1080.

6 Parsons LH, Zaccaro D, Wells B, et al. Methods of and attitudes toward screening obstetrics and gynecology patients for domestic violence. Am J Obstet Gynecol 1995;173:381-386.

7 Isaac NE, Sanchez RL. Emergency department response to battered women in Massachusetts. Ann Emerg Med 1994;23:855-858.

8 Waller AE, Hohenhaus SM, Shah PJ, et al. Development and validation of an emergency department screening and referral protocol for victims of domestic violence. Ann Emerg Med 1996;27:754-760.

9 Olson L, Anctil C, Fullerton L, et al. Increasing emergency physician recognition of domestic violence. Ann Emerg Med 1996;27:741-746.

10 Carbonell JL, Chez RA, Hassler RS. Florida physician and nurse education and practice related to domestic violence. Womens Health Issues 1995;5:203-207.

11 Rodriguez M, Bauer H, McLoughlin E, et al. Screening and intervention for intimate partner abuse: practices and attitudes of primary care physicians. JAMA 1999;282:468-474.

12 Gerbert B, Caspers N, Bronstone A, et al. A qualitative analysis of how physicians with expertise in domestic violence approach the identification of victims. Ann Intern Med 1999;131:578-584.

13 Gerbert B, Abercrombie P, Caspers N, et al. How health care providers help battered women: the survivor's perspective. Women Health 1999;29:115-135.

14 Gerbert B, Johnston K, Caspers N, et al. Experiences of battered women in health care settings: a qualitative study. Women Health 1996;24:1-17.

15 Salber P. Managed care and domestic violence: challenges and opportunities. Domestic Violence in Health Care: Initiatives for the New Millenium. Washington, DC: Family Violence Prevention Fund; 1997.

16 Feldman M. Domestic violence. In: Feldman M, Christensen J, eds. Behavioral Medicine in Primary Care. 1st ed. Stamford, CT: Appleton \& Lange; 1997:307-312.

17 Freund KM, Bak SM, Blackhall L. Identifying domestic violence in primary care practice. J Gen Intern Med 1996;11:44-46.

18 Taliaferro E. Domestic violence: the need for good documentation. Action Notes: Physicians for a Violence-free Society 1997;23:1.

19 Berrios DC, Grady D. Domestic violence: risk factors and outcomes. West J Med 1991;155:133-135.

20 Alpert EJ. Violence in intimate relationships and the practicing internist: new "disease" or new agenda? Ann Intern Med 1995;123:774-781.

21 Ferris LE. Canadian family physicians' and general practitioners' perceptions of their effectiveness in identifying and treating wife abuse. Med Care 1994;32:1163-1172.

22 Ferris LE, Tudiver F. Family physicians' approach to wife abuse: a study of Ontario, Canada, practices. Fam Med 1992;24:276-282.

23 Sugg NK, Inui T. Primary care physicians' response to domestic violence: opening Pandora's box. JAMA 1992;267:3157-3160.

24 Lee D, Letellier P, McLoughlin E, et al. California Hospital Emergency Departments Response to Domestic Violence: Survey Report. San Francisco: Family Violence Prevention Fund; 1993.

25 Kurz D. Interventions with battered women in health care settings. Violence Vict 1990;5:243-256.

26 Kurz D. Emergency department responses to battered women: resistance to medicalization. Soc Probl 1987;34:69-81.

27 Rodriguez MA, Quiroga SS, Bauer HM. Breaking the silence: battered women's perspectives on medical care. Arch Fam Med 1996;5:153-158.

28 McCauley J, Yurk RA, Jenckes MW, et al. Inside "Pandora's box": abused women's experiences with clinicians and health services. J Gen Intern Med 1998;13:549-555.

29 Chez R, Jones R. The battered woman. Am J Obstet Gynecol 1995;173:677-679.

30 Warshaw C. Intimate partner abuse: developing a framework for change in medical education. Acad Med 1997;72(suppl):S26S37. 